\title{
Comparison of protein intake consumed by Saudi schoolchildren in healthy schools and normal schools
}

\author{
E. Alamri ${ }^{1}$ and L. ALBishi ${ }^{2}$ \\ ${ }^{1}$ Department of Nutrition and Food Science, University of Tabuk, Saudi Arabi and \\ ${ }^{2}$ Department of Pediatric. University of Tabuk, Saudi Arabia
}

Saudi Ministry of Education launched a new program in some Saudi schools, called healthy schools. The program aims to improve eating habits in a school, by involving them in nutritional-education programs, nutritional activities, monitoring children during their school meals, as well as monitoring food serving in school canteens ${ }^{(1)}$. The aim of the current study is to evaluate protein intake during school meal of Saudi schoolchildren in a healthy school and compare it with that in another school (normal school).

A total of 260 schoolchildren from two elementary schools in the city of Tabuk were recruited in the present study. One school was a healthy school $(n=110)$ and one school was normal school $(n=150)$. Children were observed at school meal time, and all food consumed by them in one meal was recorded by a trained research assistant. The portion size of the consumed food was estimated by household measures, and the nutritional information of the packed food was obtained from the packaging label. ESHA's Food Processor Nutrition Analysis software was used to analyze the dietary data. Data were analyzed using IBM SPSS Statistics for Windows, version 23 (IBM Corp., Armonk, N.Y., USA). A t test for independent samples was used to compare protein intakes of the healthy and normal schools.

Consumption of protein was significantly higher in the healthy schools with mean and standard deviation (10 \pm 2.2 grams/ day) compared to the normal schools $(4 \pm 1.3$ grams/day $)(P=0.03)$. Dairy products contributed significantly more to energy intake in healthy school $(20 \%)$ compared to the normal school $(8 \%)(p=0.01)$. Energy derived from protein was significantly higher in healthy school $(16 \%)$ than normal school $(7 \%)(P=0.02)$.

Protein consumption by Saudi schoolchildren in school meals from the healthy school was higher than the normal school. Therefore, the healthy schools programme was effective to improve protein intake in healthy school.

1. Saudi Ministry of Health (2019) available online from: https://www.moh.gov.sa/en/Ministry/Projects/Healthy-Schools/Pages/default.aspx. (accessed March 2020). 